\title{
Marcus Woof: 'Our goal is to have a dental student rep for GLADD at every dental school'
}

\author{
Interview by Kate Quinlan
}

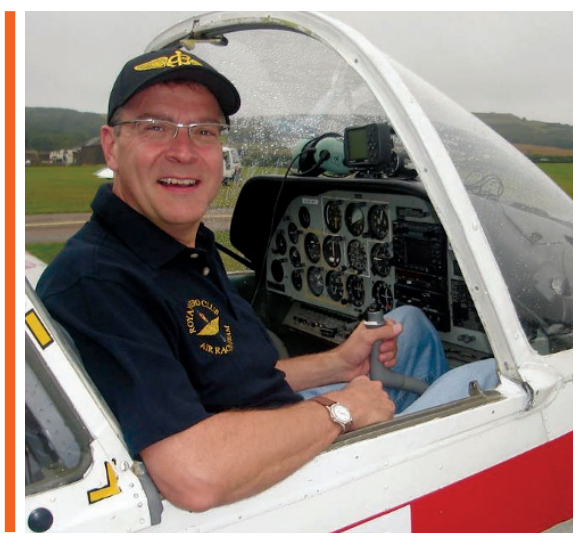

Please can you tell me a bit about your background?

I lived in East Dorset as a child and loved the outdoors and countryside. My father had long periods of poor health and unemployment, so we struggled - my holidays were the annual Scout camp. The turning point for me was the opening of a new local comprehensive school with enthusiastic and gifted teachers who nurtured and tutored half-a-dozen of us who were the first to go on to university. My parents were always very supportive but I think they were secretly worried when I went to Birmingham to study. The city was a very different place in 1976, a couple of years after the pub bombings. However, it was the best thing I ever did.

I graduated in 1980 and went straight into a very busy resident house-job in oral and maxillofacial surgery at the then Birmingham General Hospital. I did a couple of years there and I learnt and grew up a lot.

Then I took some time out to work in general practice as I thought it was important to do that, whatever your career intentions, as it is the 'bread and butter' for most dentists. After that I went back into oral and maxillofacial surgery as a registrar which was a good grounding for me because my main clinical interest has always been special care dentistry and the combined experience of ' $m a x$-fax' and general dental practice really helped.

\author{
Marcus Woof, Honorary Senior Lecturer for Disability Studies at the University \\ of Birmingham School of Dentistry, spoke to News Editor Kate Quinlan about \\ his career in dentistry and his involvement with the Association of LGBT \\ Doctors and Dentists - also known as GLADD.
}

\section{Were there other dentists in the family?}

No, there weren't. I was very frightened of going to the dentist when I was a youngster. The towed mobile dental caravans visited the school every year, and I have enduring memories of children being dragged screaming into these vans. They didn't use local anaesthesia back then to restore teeth and I became very upset. So I visited my mum and dad's dentist who was very patient and supportive - he eventually got me over this dreadful phobia. It was a bit of a family story that someone who was so afraid of the dentist eventually became one!

\section{How did you move into special care dentistry?}

Ultimately my community dental service, hospital and general practice experience led very nicely to treatment provision for people with disabilities.

I read for a Master's at Birmingham and then moved into a more senior post as Clinical Director for the CDS in Solihull where we started to develop services for adults and children with complex needs requiring special care dentistry and treatment under general anaesthesia in a hospital environment. Around that time, I also had a local role in dental public health. Both took a lot of my time and energy and it was an incredibly busy period.

Through the network of the CDS clinical directors we started to make contact with other colleagues in developing such services and the new specialty of special care dentistry.

I was invited to be on the Board of the Faculty of Dental Surgery at the English College and I was very involved with the British Dental Association and the British Society of Disability and Oral Health. Eventually, through the transitional route, I became a GDC registered specialist in special care dentistry along with other friends and colleagues who had been on the long journey with me.

The more recent massive NHS reorganisation and structural changes meant that I was drawn more into dental public health and so I worked for Public Health England before I retired last year.

I still hold my teaching post as Honorary Senior Lecturer in Disability Studies at Birmingham University School of Dentistry (the new one!).

\section{I recently interviewed Anita Desai who said that she and her to-be husband were the only two non-Welsh students in their year in the 1970s. Was the student population at your university diverse?}

I was at dental school in Birmingham from 1976 to 1980 and it wasn't that diverse. I recall that we had a couple of students who weren't white. However, a lot of my dental student friends had a similar background to me, and came from all over the UK. 
In the late 70s, did students tend to be open about their sexual orientation?

I think people were a lot more reticent in those days. There was probably one student in the Dental School who was 'out', but even so, it was difficult back then to say, 'this is who I am and this is what I am - I'm out and proud'. Surely, there were men and women in my dental school and throughout the university at that time who were gay but would never have thought of 'coming out'.

Do you think in the past those in the traditional 'professions', including dentistry, would have tried to keep their sexual orientation secret?

I'm pretty sure that was the case given anxieties about what patients might do, say or think, particularly in the 1980s with the huge issues relating to HIV at that time. In addition, the then Government implemented Section 28 legislation, which made it even more difficult for people to be open about their sexuality.

(Section 28 - the ban on local authorities promoting homosexuality or 'promoting the teaching in any maintained school of the acceptability of homosexuality as a pretended family relationship', enacted in 1988 was eventually abolished by the Labour Government in 2003.)

\section{Have times changed?}

I think they definitely have. I'm not saying that all LGBT people have the same experience (and many will continue to struggle), but I think that it's generally easier for people to come to terms with their sexuality and be open about it now. In terms of 'coming out', I didn't sort of jump out and say 'this is what I am' - you just chat to family, friends and work colleagues, and people get to know.

Time went by and I met my partner Roy in 1989. My family had been worried about me, but when they first met him they were delighted that I was happy at last and I'd met someone and they welcomed him into the family with open arms (my parents are both deceased). We have now been together 27 years and became civil partners a few weeks after civil partnership was introduced in December 2005.

One of my proudest moments was to have Roy by my side when I became President of the BDA Community Dental Services Group in 2006, and more recently at the BDA Honours and Awards last dinner last year when I was awarded Life Membership of the BDA.
Have you experienced any problems yourself in your career?

On balance, no, I haven't experienced any problems in my career relating to my sexuality, but it was an issue on very rare occasions outside of work, as every so often we would hear a comment or receive a gesture from someone we might be passing by.

\section{When did you first become aware of GLADD?}

I became aware of the organisation in the late 1980s, and in due course, joined up. I was quite quiescent as a member as it was always very London-centric.

GLADD's full name is the Association of

LGBT Doctors \& Dentists and is inclusive of all of the goals is to increase dental membership and have a dental student representative for GLADD at every dental school who will be our point of contact with the students. We would definitely like to see a dental student network to help take forward the issues that are important to them.

\section{Do you think sexuality is still an issue for today's students?}

I think perhaps young people may be more open about their sexuality these days and feel that 'this is what I am and so what?' But I'm sure there are many others who really struggle to come to terms with who and what they are, or who may have met with disapproval from their family and friends in the past.

\section{'I think that it's generally easier for people to come to terms with their sexuality and be open about it now...'}

dentists, doctors and students who identify as lesbian, gay, bisexual, trans, queer or questioning. It was formerly the Lesbian and Gay Medical Association (LGMA) and changed its name to GLADD to include dentists. I became a member of the organisation pre-GLADD.

I decided to join to have better contact with and understanding of what other LGBT dentists and doctors were doing, to share the work being done and how they dealt with equality and diversity issues, and just being themselves and living their day-to-day lives. It was also a support network and provided an opportunity to socialise.

\section{What has your more recent} involvement been with the association and any plans for the future?

I am now the Dental Representative on the GLADD Executive Committee. We meet online or in person every three months and keep in regular email contact.

For GLADD members, there are scientific and social occasions throughout the year. We have a very good interface and work jointly with the General Medical Council (GMC) on specific projects around equality and diversity, and I hope to open a similar dialogue with the General Dental Council (GDC) in due course.

A workshop with the BDA would be a very useful stating point.

GLADD has 336 medical and dental

members and students. As an association, one
Would you encourage people reading this article to join GLADD or volunteer to be a dental student rep?

Yes, certainly. Anyone who would like to join please visit: http://www.gladd.co.uk/index. php/join-us.

The website gives a lot of information and details of events and the work programme. We also intend to be more proactive and contact dental schools ourselves and promote GLADD and its activities and events.

\section{What other activities keep you busy now that you are retired?}

I am of course still teaching at the Birmingham School of Dentistry for part of the year and remain passionate about oral healthcare for people with disabilities.

Back at home, we have caught up on lots of jobs that needed to be done in and around the house and garden and more importantly have been able to get out and about walking in the great outdoors whenever we like. The spontaneity of being able to throw your walking boots in the car boot and pack a flask and sandwiches for a hike around the Malvern Hills whenever you like is a simple but real pleasure!

We spend a lot of time at Shobdon airfield in Herefordshire, where I obtained my pilot's licence in 2002. Out static caravan is a second 'home' to us, so there's lots of flying and exploration of Herefordshire, the Welsh Marches and beyond by foot and by air. 